\title{
The Relationship Between Responsibility and Decision-Making
}

Features Among Female Volleyball Coaches in Kerman

Maryam Kafinejad

International Journal of Advanced Biological and Biomedical Research

Journal DOI: $10.18869 / \mathrm{IJABBR}$

ISSN: $2322-4827$

CODEN (USA): IJABIS

$\underline{\text { http://ijabbr.com }}$
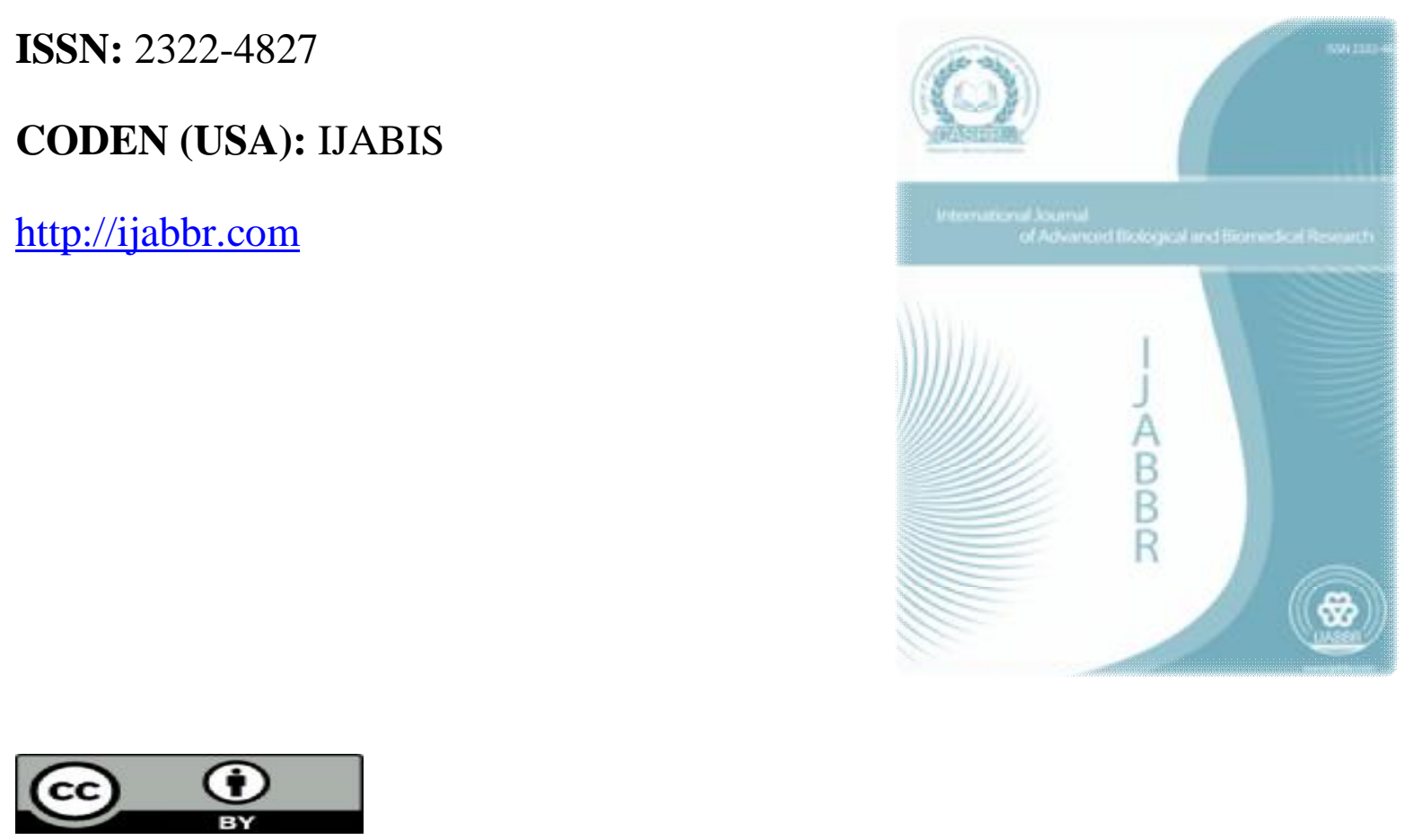

Copyright (C) 2018 by authors and the Sami Publishing Corporation(SPC). This work is licensed under the Creative Commons Attribution International License (CC BY4.0).

https://creativecommons.org/licenses/by/4.0/ 


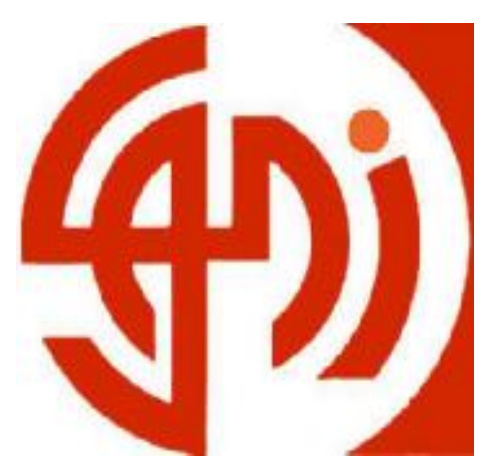

Available online at http://ijabbr.com

International Journal of Advanced Biological and Biomedical Research 6(1) (2018) 66-75

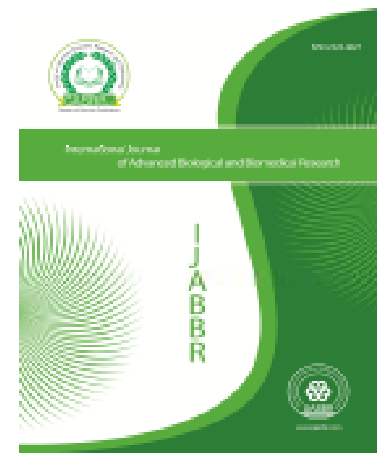

\title{
The Relationship Between Responsibility and Decision-M aking Features Among Female Volleyball Coaches in Kerman
}

\section{Maryam Kafinejad*}

Expert Responsible Physical Upbringing Office, Technical and Vocational University, Kerman, Iran.

\begin{abstract}
The purpose of this study was to investigate the relationship between responsibility and decision-making features among female volleyball coaches in Kerman. The research was correlational. The statistical society of this study included all coaches of volleyball women in Kerman in 2014 including 400 people. According to the Morgan table, 196 people were selected by sampling method. In this research, two standard questionnaires including the Gaff Responsibility Questionnaire (1951) with a validity of 0.86 and reliability of 0.896 and Scott and Bruce (1995) questionnaire with a validity of 0.84 and reliability of 7760 had been used. To analyze the data according to the measurement scales, objectives and research questions, descriptive statistics such as frequency, frequency percent, and column charts were used. To test the hypothesis of the research, the inferential statistics of $k-s$ test were used to normalize the data and Pearson correlation coefficient used to investigate the research hypotheses. The results of the research showed that $8.2 \%$ responsibility of female volleyball coaches were low, $14.8 \%$ average, $74.5 \%$ high and $6.2 \%$, very high. The dominant decision making style was $37.2 \%$ rational, $27 \%$ intuitive, $13.8 \%$ dependent, $11.7 \%$ instantaneous and $10.2 \%$ avoidant. Other results of the study showed that there was a direct and significant relationship between responsibility and decision making features of female volleyball coaches in Kerman. There was also a direct and meaningful relationship between responsibility and the rational decision of female volleyball coaches in Kerman. There was a reverse and significant relationship between responsibility and dependent, spontaneous and avoidant decision-making of female volleyball coaches in Kerman. However, there was no meaningful relationship between responsibilities with the intuitive decision making of female volleyball coaches in Kerman.
\end{abstract}

(c) 2018 Published by CASRP Publishing Company Ltd. UK. Selection and/or peer-review under responsibility of Center of Advanced Scientific Research and Publications Ltd. UK.

Keywords: Responsibility, Decision-M aking, Coaches, Female, Volleyball, Kerman

*Corresponding author: M.Kafinejad@gmail.com

(c) 2018 The Authors. This is an open access article under the terms of the Creative Commons Attribution-Non Commercial- No Derives License, which permits use and distribution in any medium, provided the original work is properly cited, the use is non-commercial and no modifications or adaptations are made. 
M aryam Kafinejad / International Journal of Advanced Biological and Biomedical Research (2018) 7(1) 66-75

\section{Introduction}

The growth and development of any society and country depends on the efficient and desirable performance of organizations and institutions and, consequently, the efficient and desirable performance of people working in these institutions and organizations. In today's society, many employees and officials are accused of failing to take responsibility for their activities in the organization. The burden on officials is like the responsibilities and tasks that are an introduction to achieving the goals. The person in charge of the task accepts a series of activities or supervises others (Certo, 2004). So, the person who is responsible may deal with caution in new situations; as a result, his performance is overshadowed (Lizcook, 1995).

The term "responsibility" is used for various purposes; expressions such as responsible use of the environment, self-employed behavior in work, responsible assignments, ethical responsibility, etc. in daily conversations and the nature of the matter is the same, and the purpose is to use the power of thought, logic, and conscious decision making for the purpose of knowing their tasks and performing them accurately. When it comes to personal responsibility, the rays of performing responsible action are related to one's person and his personal life, and the benefits of doing responsible behavior in the social responsibility are related to the community, the public and everyone (Badley, 1985). Today, social responsibility goes far beyond the sphere of activity and influence of the past, which was "humanitarianism". Social responsibility in the field of sport to achieve sustainable development has found its role in providing preventive solutions to social challenges and leisure time, physical and mental health, and etc (Vasilescu et al., 2010). Responsibility is a sensitive and appealing issue in recent years; it is a fundamental factor in the survival of any organization (Royaroee and M ehrdost, 2009). Responsibility advocates arguing that large organizations not only need to be accountable as the key to the organization in order to meet the needs of stakeholders, but also to meet the needs of the stakeholders, including the community, customers and suppliers (Holmqvist, 2009).

Responsibility is characterized with names such as conscientiousness, social function, responsible business, responsibility of citizens and social responsibility of a person, and means a set of duties and responsibilities that the responsible should maintain in order to care for a society in which is committed to doing things that protect and promote the welfare of the community and the interests of the organization (Choi and Gray, 2008). In a study published under the title of accountability Pyramid, Carroll gave four categories of responsibilities to each individual. These are economic, legal, ethical and altruistic responsibilities that are used in this research to measure the coach's responsibility from this model. On the other hand, decision making is one of the most important processes in the sports organization and is considered as the main task of managers and coaches of all levels; so that, some scholars believe that "all management is decision-making" (Pamela, 1996). Contez believes that the existence of a plan, program, policy and policy depends on the existence of a decision. He also believes that the manager usually considers his or her main task as decision-making, because he always has to think about what to choose, what to do, how to do the tasks, how people are divided, what, who, what time, where and how to do? Coaches are confronted with situations in which they are forced to make decisions, and this position expresses the role and importance of decision-making responsibilities among managers and coaches, and considers it vital in coordinating operations to achieve goals (Sa'adat, 2017), and the factor in the success and failure of a group, team and organization (Hadizadeh M oghadam and Tehrani, 2011).

Deciding is choosing a strategy among two or more options in a precautionary approach and in order to achieve a specific goal with the least risk (Cervone, 2005). Therefore, the decision making is the core of the planning process. An application cannot exist unless a decision is made. Managers are always faced with the conditions that need to make a decision on their behalf. This also has a very important influence and position of decision making in all tasks of managers and authorities. In the field of sport, the success or failure of any team depends largely on the powers of team coach (Ramezani, 2007). Therefore, coaches are professional in decision making, and the quality of these decisions determines the team's success in achieving the goals of the club. Each coach determines a particular method or methods based on his decision and choosing the appropriate coaching decision is a very important factor for the success of the team and the club (Olivera, 2007).

Some thinkers know the management of decision making as the basis of all the duties of managers, and others consider decision making as one of the duties of managers. Herbert Simon considers decision making as the essence of management. In his opinion, management is nothing but a decision, and a successful manager can be a successful decision maker (Mortezaei Moghaddam, 2001). However, it should be noted that the nature and complexity of the work of sports team's coaches requires deal with a variety of decisions and the factors causing 
psychological stress are likely to interfere in their decision-making process. Since, coaches are faced with a limited time for decision making and do not always have the freedom and authority to make decisions, so these two factors give rise to more psychological stress for coaches (Weinz and Koontz, 2003). Research reveals that, coaches according to personality traits, type of management, and viewpoint that guide the team choose a particular type of decision making style (Tatum et al., 2003).

Different categories of decision making methods have been presented and each of the categories is different depending on which individual, organizational, and environmental factors are involved in how people react and behave when faced with decision making conditions. Starr (1998) argues that, decision making is the basis of all the tasks that the manager is doing in the organization (Martin, 2004). Newman considers the quality of management's function as a function of decision quality, and believes that decision alone is the main task of the manager, because the quality of plans and programs, the effectiveness of the strategies and the quality of the results obtained from them, all depend on the quality of decisions that the manager adopts. According to Kast (1994), the decision to coordinate operations is important in achieving the goals (Sa'adat, 2017). One of the factors that can lead sports team instructors in decision making and sensitivity towards it is a sense of responsibility in them.

Coaching in sports psychology has attracted particular attention; coaches are the mainstay of the sports teams. The coach among three athletes, coaches and spectators is a strong organizer and foundation of any sports or team development. Therefore, effective coaching involves various roles and styles. Today coaching is among the most difficult jobs. A good trainer needs to have extraordinary skill and knowledge to develop athletes. The working conditions in the coaching profession are difficult, as in this profession, the coaches are under the precise, careful and rigorous vision of people such as audiences, players, sports managers, media reporters and critics of society (Mosded, 2001). There are many factors in the success of managers for their effectiveness, including coaching knowledge, commitment and decision making about factors such as knowledge, emotional intelligence, philosophical intelligence and responsibility. One of the skills needed by coaches for better success is the ability to make the right decisions, because coaching is team management and decision making is the most important condition of management.

The results of Reisi's (2013) research showed that, there is a relationship between the social responsibility of managers of Kerman roads and transportation department and their decision making style; so that, managers who are more responsible use more rational and intuitive decision making style and managers who are less responsible use more avoidant and spontaneous dependent decision-making styles. Studies also reveal that, officials and employees who are not responsible to organizations do not show loyalty to the organization (Walker, 2009), the sense of individual responsibility is not satisfactory (Pitts, 2010), and if they are not responsible for organizational decisions, they do not care (Mitus, 2006) and do not believe in organizational goals and values. As a result, negative consequences, including disruptions in performance, and among managers and officials of these factors, lead to incorrect decisions that may cause serious damage to the organization (Tsaie, 2003). Research on the relationship between responsibility and decision making among coaches is extremely important. Understanding this in designing the great strategies of relevant affairs for professionals is very important. Basically, the issue of responsibility has become a pervasive phenomenon and even a major concern for sports organizations. Coaches' accountability by regulating the relationships of components of each system helps to reduce the complexity of relationships and predicts the behavior of others. This contributes to increasing social trust and thereby increasing the safety sense of members in the team and society and reducing their cognitive dissonance (Fistring, 1959).

Clubs and sports teams are no exception to this, so if they do not feel responsible in sport teams such as volleyball, or their responsibilities in the club are weak, then there may not be good ways to make good decisions which leads to team formation or dissatisfaction with athletes and team officials. However, scientific knowledge about the extent of coaching responsibilities effect and decision making methods requires field and scientific research; so, its results can be used to guide and lead the teams. This research seeks to achieve this goal, namely, a field study of relationship between responsibility and decision-making features among female volleyball coaches in Kerman. Therefore, the questions that the research has sought to answer them is that; what is the status of female volleyball coaches in Kerman? What are the features of decision making for female volleyball coaches in Kerman? Are coaching decision-making features influenced by their degree of responsibility? So, the basic question of the research is, whether there is a relationship between responsibility and decision-making features among female volleyball coaches in Kerman? 
M aryam Kafinejad / International Journal of Advanced Biological and Biomedical Research (2018) 7(1) 66-75

\section{Research background}

Aghaee et al. (2002) in his research entitled "Investigating decision making processes of physical education managers in universities affiliated to the Ministry of Science, Research and Technology" showed that, the level of readiness of subordinates alone did not determine the decision maker's style, but the manager's level of readiness also was effective in determining his decision making style. Kurdlo's research results (2008) showed that, there was no significant difference between the responsibility of high school male and female students. Also, the results indicated a significant relationship between sense of security, belonging and high self-esteem with responsibility.

Hadizadeh Moghaddam and Tehrani (2011) in their research entitled "Explaining the Relationship between Emotional Intelligence and Managers Decision making Style" concluded that, there was a significant and negative relationship between emotional intelligence and rational decision making and avoidance styles among managers. They also found that there was a significant and positive relationship between the emotional intelligence and the intuitive decision making style of the managers. There was no significant relationship between emotional intelligence and direct and indirect decision making styles. The predictive model of decision making which relationship with the emotional intelligence of managers is confirmed using logistic regression presented.

Aghaei (2010) explored, "Determining the readiness levels of managers and staff of physical education in universities of the country to make effective decisions in their organizations". The results showed that the level of preparedness of subordinates alone was not a determining factor in the decision maker's style, but also the level of readiness of the manager himself was effective in determining his decision making style. Moradi et al. (2012) had conducted a research aimed at investigating the relationship between managers' decision making and employee responsibility. The results showed that, the managers of Semnan University were more likely use individual decision making. There was a positive and significant relationship between managerial decision-making practices (group, consulting, and partnership) with employee's responsibility. There was a negative and significant relationship between personal decision making and employee accountability. The participatory decision-making methodology of managers was the most important predictor of employee accountability.

Ghalavandi et al. (2014) conducted a study entitled "The Study of the Relationship between Social Responsibility and Urmia University Employees' Teamwork". The results showed that: 1 . There was a significant relationship between social accountability (0.49), legal liability (0.57), economic responsibility (0.46), moral responsibility $(0.50)$ and social responsibility 0.15$)$ and teamwork. 2 . Regression coefficients showed that, economic responsibility $(\beta=0.13)$ and legal liability $(\beta=0.53)$ could positively and significantly predict teamwork. Lovane (2003) examined "the impact of corporate culture on decision making and style", and concluded that according to the type of culture dominant in society, employees had different expectations from their managers and leaders, which led to the adoption of the style with special way of leadership. There was a positive relationship between the organizational culture of task forces and decision-making style of avoidance in employees. There was also a positive and significant relationship between the supporting culture and dependent decision making.

Cruz (2007) in a study entitled "Dynamics of Manufacturing Networks with Organizational Responsibility through Integrated Environmental Decision Making" believed that changes in the flow of production were associated with prices and levels of social responsibility, in order to achieve a balanced model for the production network. Francisco et al. (2007) concluded in a research entitled "The Relationship between Environmental Responsibility and Performance in Guesthouses" concluded that, there was a positive and strong relationship between the two variables. There was a meaningful relationship between tourism products and the cultural, social, economic and environmental environment. Norton (2010) explored the "study of the relationship between the theory of motivation-health of Herzberg and the theory of Likert management". The research was conducted using correlation and statistical population of managers and employees of transportation organization. The results of the research showed that managers who were oriented towards employee-oriented management styles interfere with people's participation in decision making, which leads to more employee satisfaction with the work. There was a meaningful relationship between the style of rational management and employee participation in decision making.

Hess and Bacigalupo (2011) conducted a study entitled "Promotion of decision making and decision-making processes through the use of emotional intelligence skills". This research had been conducted descriptively. The statistical population was the staff and managers of the education organization. The statistical sample was composed of 31 managers and 382 employees. A questionnaire was used to collect information. The results of the research showed that organizations and their employees could benefit from the development and application of 
M aryam Kafinejad / International Journal of Advanced Biological and Biomedical Research (2018) 7(1) 66-75

emotional intelligence behaviors. In fact, the researchers concluded that emotional intelligence skills could improve group decisions and outcomes.

Amzat and Idris (2012) conducted a study entitled "Structural Equation M odeling of Managers Decision Style with Job Satisfaction of Staff Students at the Malaysian Research Institute". The research method was descriptive and the statistical population included all employees of the Malaysian University of Science in 2011 and 323 individuals selected randomly. Data gathering tool was a researcher made questionnaire and statistical analysis was performed with Amos software. It was concluded that the university has chosen an analytical decision-making method. In addition, it was found that health factors predict job satisfaction at the university.

\section{Methodology}

This research has been done using correlation method. The statistical population includes 400 coaches from Kerman female volleyball teams in 2015, which, according to the Morgan table, 196 have been selected by sampling method. To measure the variable of responsibility, the Gaff Responsibility Scale (1951) has been used. This scale is designed to measure the responsibility of employees and authorities and has 35 articles. The above test is used to measure features such as legal, economic, ethical, and altruistic responsibility. It is designed with Likert scale from very low to very high, and its score is from 1 to 5 for each question. Sa'adi Shamir (2004) listed its validity as 0.86 . Rezaee (2000) obtained the reliability coefficient of this questionnaire with Cronbach's alpha of 0.79 and Sa'adi Shamir (2004) through a re-test method of 0.81. Leadership Decision Style Questionnaire: This questionnaire has been prepared by Scott and Bruce (1995) and translated into Persian by Hadizadeh Moghadam and Tehrani (2011) and its validity and reliability measured in Iran. The questionnaire consists of 25 questions and 5 questions are devoted to assessing each of the decision-making styles. The scores range is from 25 to 125 in this questionnaire. A high score in each dimension indicates that the dominant style of decision-making is by the manager. The scoring questionnaire for general decision making styles is based on a 5-point scale; each score is as follows: never $=1$, rarely $=2$, sometimes $=3$, often $=4$, always $=5$. Scott and Bruce (1995) identified the validity of this questionnaire and Hadizadeh Moghadam and Tehrani (2011) have a formal validity of 0.84 . Scott and Bruce (1995) have listed the reliability coefficients of each of the rational, intuitive, dependent, spontaneous, and avoidant subscales of Cronbach's alpha as $0.85,0.84,0.86,0.49$ and 0.87 , respectively. Jahromi (2013) obtained the reliability coefficient of each the sub-scales as $0.79,0.66,0.79,0.83$ and 0.80 respectively. In this research, Cronbach's alpha has been used to examine the internal consistency of the questionnaires, which obtained 0.99 for the responsibility variable and 0.78 for the questionnaire reliability of decision-making styles. For data analysis, descriptive and inferential statistics including mean and standard deviation and Pearson correlation coefficient test have been used and all statistical steps performed using spss21 software.

\section{Findings}

\subsection{Descriptive statistics of variables}

Table 1

Mean and standard deviation of research variables.

\begin{tabular}{lc}
\hline Variable & Standard deviation \pm Mean \\
\hline Responsibility & $3.58 \pm 0.515$ \\
Decision making styles & $3.35 \pm 0.489$ \\
Legal & $0.544 \pm 3.50$ \\
Economic & $3.65 \pm 0.725$ \\
Moral & $3.60 \pm 0.608$ \\
Altruistic & $3.58 \pm 0.538$ \\
Rational & $3.94 \pm 0.577$ \\
Intuitive & $3.75 \pm 0.642$ \\
Dependent & $3.07 \pm 1.161$ \\
Spontaneous & $2.59 \pm 0.709$ \\
Avoidant & $2.10 \pm 0.686$ \\
\hline
\end{tabular}




\subsection{Check assuming normal distribution of variables in the sample}

The results of the Kolmogorov-Smirnov test regarding responsibility scores, decision-making styles, and the dimensions of those respondents. According to the results of Table 2, the $z$-value obtained for the main variables which significance level is greater than the measurement level $(0.05)$, therefore, the hypothesis is not accepted. It can be concluded that, the distribution of these variables is not statistically different from normal distribution. So, the data of the main research variables follow the normal distribution.

Table 2

The result of the Kolmogorov-Smirnov test for variables.

\begin{tabular}{lccc}
\hline Variable & No. & ZAmount & Sig. \\
\hline Responsibility & 169 & 1.222 & 0.186 \\
Decision making styles & 169 & 1.963 & 0.092 \\
Rational & 169 & 2.288 & 0.001 \\
Intuitive & 169 & 1.780 & 0.142 \\
Dependent & 169 & 2.053 & 0.001 \\
Spontaneous & 169 & 1.876 & 0.112 \\
Avoidant & 169 & 1.974 & 0.10 \\
\hline
\end{tabular}

\subsection{Hypothesis 1 . There is a significant relationship between responsibility and decision-making features of female volleyball coaches in Kerman}

Data analysis using Pearson test showed that the correlation coefficient between two variables of decisionmaking factors is equal to 0.41 with $p$-value (significant) of 0.043 , which is smaller than the significance level of $\alpha=$ 0.05 . Therefore, there is a positive and significant relationship between the responsibility and the decision making features of female volleyball coaches in Kerman. That is, the more responsibility, the more decision-making features will be. The determination coefficient between two variables is equal to $0.021(=0.021)$, or $2.1 \%$ of the change between the two variables is common $(2.1 \%$ of the changes in the features of the decision making is justified with responsibility) (Table 3).

\section{Table 3}

Pearson correlation test statistics related to the relationship between responsibility and decision-making features.

\begin{tabular}{lccc}
\hline & \multicolumn{3}{c}{ Decision making features } \\
\cline { 2 - 4 } Variable & Correlation Coefficient & Sig & $\mathbf{R}^{2}$ \\
\hline Responsibility & 0.145 & 0.043 & 0.021 \\
\hline
\end{tabular}

\subsection{Hypothesis 2. Responsibility has a significant relationship with rational, intuitive, dependent, spontaneous, and avoidant decisions of female volleyball coaches in Kerman}

Data analysis using Pearson test showed that, the correlation coefficient of responsibility with the rational, intuitive, dependent, spontaneous and avoidant decision has been respectively $0.227,0.116,-0.191,-0.32$ and -0.194 with significant level of $0.001,0.106,0.007,0.001$ and 0.006 respectively which except for significant intuitive decision making, the remaining variables are smaller than the significance level of $\alpha=0.05$. Therefore, there is a significant relationship between responsibility and rational, dependent, spontaneous and avoidant decision making of Kerman female volleyball coaches. Based on the correlation obtained, there is a positive relationship between the responsibility and the rational decision of the coaches, that is, the greater the responsibility, the more rational the decision will be. However, there is a negative relationship between responsibility and dependent, spontaneous and avoidant decision making, that is, the greater the responsibility, the dependent, spontaneous and avoidant decision making of the coaches will be less. Also, the determination coefficient between responsibility with rational, dependent, spontaneous and avoidant decision is $0.052,0.0336$, 0.102 and 0.0338 , respectively, or the rational, dependent, spontaneous, and avoidant decision changes are explained $0.052,0.0336,0.102$ and 0.038 , respectively with responsibility (Table 4). 
M aryam Kafinejad / International Journal of Advanced Biological and Biomedical Research (2018) 7(1) 66-75

Table 4

Pearson correlation test statistics related to the relationship between responsibility and rational, intuitive, dependent, instantaneous and avoidance decision making.

\begin{tabular}{lccc}
\hline & \multicolumn{3}{c}{ Responsibility } \\
\cline { 2 - 4 } Variables & Correlation Coefficient & Significant level & $\mathbf{R}^{2}$ \\
\hline Rational & 0.227 & 0.001 & 0.052 \\
Intuitive & 0.116 & 0.106 & 0.013 \\
Dependent & -0.191 & 0.007 & 0.036 \\
Spontaneous & -0.32 & 0.001 & 0.102 \\
Avoidant & -0.194 & 0.006 & 0.038 \\
\hline
\end{tabular}

\section{Conclusion}

According to the results, there was a direct and significant relationship between responsibility and decisionmaking features of female volleyball coaches in Kerman $(r=0.145)$, ie, the more responsibility of volleyball coaches, the better they would be in decision-making. These results indicated that, if the relations of individuals are governed by a hierarchy of rules and regulations (3.95) in the volleyball clubs, everyone complies with their duty (3.38), coaches enjoy serving the people (3.14), forgiveness and sacrifice have been the basic principles of life and work of coaches (3.32), overcome the problems of athletes (3.86), do a good thing (3.54); then, the couches review their sources of information before they decide (3.87), they think a lot when making a decision (4), they trust to their feelings and reactions when making a decision (3.85) rely on their internal perception when deciding on their own (3.83), they are less dependent on others (3.63), and do not refuse to make a decision (2.59).

These results were consistent with the findings of Moradi et al. (2012) that stated, there was a positive and significant relationship between managers' decision making and staff responsibility, and Moore's (2008) findings that, ethical commitment was an important factor in decision making and Francisco et al. (2007) showed, there was a relationship between environmental responsibility and the efficiency. Decision making is one of the most important processes in the organization and it is considered as the main task of managers at all levels. Some experts believe that all management is decision-making. Kuntz believed that the existence of a plan, policy is related to decision making. He also believed that the principal's main responsibility is to make decisions, because he always has to think about what to choose, what to do, how to do the tasks, how, when, where and how to Do? (Hadizadeh M oghadam and Tehrani, 2008) Deciding as the first task of the manager in the organization of affairs is so important that some thinkers have defined decision making a decision network and management as a decisionmaking act.

Based on the results, there was a direct and significant relationship between the responsibility and the rational decision of female volleyball coaches in Kerman $(r=0.145)$, ie, the greater the responsibility of female volleyball coaches, their decision making was more rational. When coaches are committed and accountable to their assigned duties, they will seek to raise their information and make logical and scientific decisions in order to do their job well and respond to the club's issues.

These results indicate that if the system of promotion and appointment of coaches in the clubs of the province is based on legal requirements (3.58), to consider timely payment of taxes as a social duty (3.74), pay attention to their human duties more than the profitability of the club. (4/06), and students' satisfaction is more than personal salary and benefits (3.85); in this case, the manager's coaches to ensure they have the correct facts will re-examine all sources of information before deciding (3.87), makes decisions in a completely rational and systematic way (4.03), makes decisions in urgent, immediate and logical decisions (4.14), identify and check all the different options when deciding (4) and decides entirely logical (rationally) in critical and vague conditions (3/86). These results are consistent with the findings of Moradi et al. (2012) that there is a positive and significant relationship between rational decision making and staff accountability, and Moore's (2008) findings that, ethical commitment is an important factor in decision making. Educate responsible and committed people is one of the most important and fundamental goals of any educational system, since educating responsible and dependent forces on internal values and conscientiousness is one of the important factors in the development and progress of each country and the training of stable characters who are less under the impact of situations and conditions and act according to their criteria and values are priorities of each educational system. In organizations, responsibility is 
closely related to conscientious work which it is also related to ethical conscience, so it can be concluded that those responsible are people with strong moral consciences that spontaneously with self-control all do their best to use their maximum ability to perform desirable tasks.

The results of the study showed that, there was no direct and meaningful relationship between responsibility and intuitive decision making of female volleyball coaches in Kerman $(r=0 / 116)$. Thus, the responsibility of female volleyball coaches did not play any role in their intuitive decision making due to the fact that the intuition decision making is dependent on the person's intrinsic qualities and personality and did not relate to ethical duties such as high responsibility. These results indicated that the responsibility and having conscience did not make the coaches decide on their own insight and inner freshness that they think it is right to do (4.21), or, when deciding pay attention to individual insight (intuition) (3.66), trust their inner feelings and reactions (3.85), and make decisions that they feel right (3.83). These results are not consistent with the findings of Moradi et al. (2012) and Moore's (2008) findings which can be due to the differences in the statistical population of the research mentioned, the models for measuring the variables studied, the sample size, and so on.

Based on the results, there was a reverse and significant relationship between responsibility and decision making between female volleyball coaches in Kerman $(R=-0.191)$, ie, the greater the responsibility of female volleyball coaches, they have less dependence on others when deciding. Then, when the coach considers himself responsible for the club and success and failure of the members and also accountable to his clients, then he tries to raise his information in different areas and make a decision that is technically beneficial to the players and the club's success and will not be dependent on others. These results indicated that if the club instructors receive salary and benefits according to the administrative regulations (3.31), the volleyball students' satisfaction is important to them (3.83), they will be able to address the problems of their students to solve their problems (3.11), during the activity of clubs, they are only thinking about teaching (3.35) and entering groups and communities with the good intentions (3.54), then as coach in making important decisions based on what others say do not work (3.04), when they are faced with important decisions, they are less reliant on other people (3.54), when deciding need helping from others less, (39.21) and decide less with the support and guidance of others (3.26). These results are consistent with the findings of Moradi et al. (2012) and the findings of Francisco et al. (2007). The responsible person loves doing his duties and responsibilities, does not leave the burden of work, does the today's work, and sometimes he does not think about anything other than serving the society and the people. Among the social organizations, "education" has a high rank due to its critical role in creating knowledge, abilities and moral education of students. Accepting the responsibilities that we do not deserve are the same as don't doing it, since it will both raise the level of expectation and ultimately lead to disappointment and desperation. Accordingly, firms should acquire the skills and competency necessary to fulfill their main mission.

Other results of the research showed that, there is a reverse and meaningful relationship between responsibility and spontaneous decision-making on female volleyball coaches in Kerman ( $r=-0.32)$, ie, the greater the responsibility of female volleyball coaches, they will make less a decision instantaneously without reason and study when deciding. When the individual coach is committed and responsive to her duties and obligations, then he will act reasonably when making a decision and will not decide without considering the consequences of the decision on the success of the club and the players. These results indicated that if the club's instructors were to be arranged in a way to act on their duty (3.38), believe that it is the right of people to have the best training (3.35), to act on their own duty (3.85), the club's survival have been essential for them (3.64) and spend more time on the amount of commitment to the club's problems (4.01); then, they feel less urgent when making a decision (3.19), less willing to make final decisions in the shortest possible time (19.21), they will not make immediate decisions when faced with a decision-making position (2.83). These results are consistent with the findings of M oradi et al. (2012) and Moore (2008). The strength of any organization should be in its measurement ability, responsiveness and accountability, such as efficiency, profitability and quality. If the club does not pay attention to these principles, it is weak and sick. Also, it will not feel comfortable if it interferes in unplanned affairs such as politics, emotional affairs, social affirmation and denial, and the creation of structures related to power relations. Responsibility is always with authority; then, everyone who is liable is actually claimed to have authority and, on the contrary, everyone who has authority is responsible. In Drucker's view, when a firm is asked to accept responsibility for solving one of the social problems, one need to think carefully about whether the dominant power is legitimate in this responsibility, if this authority is not legitimate, accepting the responsibility of the problem disclosure is, in fact, usurpation of responsibility. 
M aryam Kafinejad / International Journal of Advanced Biological and Biomedical Research (2018) 7(1) 66-75

According to the results, there is a reverse and significant relationship between the responsibility and the avoidance decision of female volleyball coaches in Kerman $(r=-0.194)$. That is, the greater the responsibility of female volleyball coaches, they leave decision-making less. It is may because due to this fact that when coaches feel responsible and find themselves responsible for the success of the club, they will no longer be in a position to decide when they need it and take the decision and do not postpone it.

These results indicated that, if the material rewards in clubs have been more important than the nonmonetary rewards for coaches (4.23), the interests of the stakeholders are more important than the athletes (3.65), pay more attention to the club than the people and citizens (3.35), and pretending to advance their goals (3.24), then, when dealing with the problem (problem or opportunity), the decision will be postponed as far as possible (2.45), refrain from any reaction to the problem (2.69) and strives to avoid decision-making as much as possible (3.27). These results are consistent with the findings of Moradi et al. (2012), Ghalavandi et al. (2014) and Asgari et al. (2011). Responsibility is one of the areas of human conscience that emanates from the ethics of work and determines the boundaries between right and wrong. If individuals especially managers and educators have been responsible, will always be responsible for making decisions and less avoid adopting a decision.

\section{Practical suggestions}

When educating the trainers, they will become more accountable for their ethical and professional issues.

It is suggested that the system for promotion and appointment of coaches in the province clubs is subject to legal regulations and coaches take into account their human duties more than the profitability of the club and students' satisfaction is more important than personal benefits and privileges.

- Club instructors receive the salary and benefits according to the administrative regulations, the students' satisfaction have been important to them, they are involved with the problems of the students to solve them. During the activity of the clubs, they are only thinking about learning and entering into groups and communities in order to work well.

The club's instructors believe that everyone should act on his job. To believe that, it is the right of people to have the best education, they are duty-bound to do their job, the club's survival is essential to them, and spend more time devoting the amount of legal commitment to the problems of the club.

- It is suggested that educators not consider material rewards from clubs more important than nonmonetary rewards, not to consider stakeholder interests more important than athletes, to pay more attention to citizens than clubs and not to pretend to advance their goals.

\section{References}

Aghaei, N., 2010. Comparison of managers readiness level and staff of physical education in universities of the country and its relation with effective decision making in the organization. J. Sport Manag. Motion Detect., $12,69-79$.

Aghaei, N., Vekuse, H., Chian, H., Azar, A., Ehsani, M ., 2002. Investigating the decision makers of physical education managers of universities affiliated to the ministry of science. Res. Technol. Q. J., 14, 93-98.

Amzat, I.H., Idris, D.A.R., 2012. Structural equation models of management and decision-making styles with job satisfaction of academic staff in M alaysian research university. Int. J. Educ. Manag., 26(7), 616-645.

Cereto, S.C., 1989. Principles of modern management, functions and systems. Massachusethe: Allyn \& Bacon, Inc.

Cervone, H.F., 2005. M aking decisions. International Digital Library Perspectives, 21(1), 31.

Choi, D.Y., Gray, E.R., 2008. Socially responsibility entrepreneurs: What do they do to create and build their companies? Bus. Horiz., 51(4), 341-352.

Francisco, J.G., Rodr, G., Yaiza del, M.A.C., 2007. Relation between social-environmental responsibility and performance in hotel firms. Int. J. Hospit. Manag., 26(4), 824-839.

Ghalavandi, H., Kabiri, A., Sultanzadeh, V., 2014. The relationship between social responsibility and teamwork of Urmia university employees. Appl. Sociol., 23(1), 111-120.

Hadizadeh Moghaddam, A., Tehrani, M., 2011. The relationship between emotional intelligence and managers decision style. Two-M onthly Journal of Daneshvar Behavior, 47, 271-283.

Hess, D., Bacigalupo, A.C., 2011. Enhancing decisions and decision-making processes through the application of emotional intelligence skills. M anag. Decis., 49(5), 710-721. 
Kurdlo, M., 2008. Examination of factors affecting the responsibility of high school adolescents at home and at school. J. Psychol. Educ. Sci., School Growth, 13, 4-11.

Lizcock, B.R., 1995. Management types among male and female managers (Translated by: M. Iran Nezhad Parizi). Tehran: Modiran.

Lovane, A., 2003. The culture driver sixty of western conceptions.

Mitus, J.S., 2006. Organizational socialization from a content perspective and its effect on the affective commitment of newly hired rehabilitation counselors. J. Rehab., 72(2), 12-20.

Moradi, F., Bidokhti, A., Akbar, A., Shahriyaripour, R., 2012. Investigating the relationship between managers decision-making methods and employees' responsibility (Case study of Semnan University). Q. J. Islam. Cult., Second Year, No. 4.

Mortezaei Moghadam, Z, 2001. The effect of the philosophical minds of managers in their decision making at Ferdowsi University. Master's Thesis of Ferdowsi University.

Oliveira, A., 2007. A discussion of rational and psychological decision making model. Electron. J. Bus. Ethies Organ. Stud., 12(2), 12-13.

Pamela, C., 1996. Decisions, decisions. J. M anag. Med., 10(6), 43.

Pitts, R., 2010. Organizational socialization of physicians into a large medical group practice. Dissertation Submitted in Partial Fulfillment of the Requirements for the Degree Doctor of Philosophy, Walden University.

Ramezani, A.R., 2007. The effect of accounting information on the decisions of bank managers (Case study: Managers of Banks in East Azarbaijan Province, Zanjan and Ardebil). J. Facul. Admin. Sci. Econ. Univ. Isfahan, 19(1), 87-96.

Saadat, E., 2017. The decision making process in the organization. Tehran University.

Sa'ati Shamir, A., 2004. The investigation of the relationship between Browsensky identity styles (Informational, Normative, Confusion/Avoidance) with general health and responsibility in Tehran University students. Master's Degree in Psychology Teacher Training.

Scott, S.G., Bruce, R.A., 1995. Decision-making style: The development and assessment of a new measure. Educ. Psychol. Meas., 55(5), 818-831.

Tatum, C.B., Eberlin, R., Kottraba, C., Bradberry, T., 2003. Leadership, decision making and organization justice. J. Manag. Decis., 1007p.

Tsaie, Y.Y., 2003. A case stndy on the work values and good work. Roznet.

Vasilescu, R., Barna, C., Epure, M., Baicu, C., 2010. Developing university social responsibility: A model for the challenges of the new civil society. Procedia Soc. Behav. Sci., 2, 4177-4182.

Walker, W.J., 2009. Predicting two types of proactive socialization tactics: The roles of context, experience, and age. A Dissertation Presented to the Academic Faculty, in Partial Fulfillment of the Requirements for the Degree Doctor of Philosophy in the College of Management, Georgia Institute of Technology.

Weinz, H., Koontz, H., 2003. Management: A global perspective. International Edition, Tenth Edition, New York, 119.

How to cite this article: Kafinejad, M., 2018. The Relationship Between Responsibility and Decision-Making Features Among Female Volleyball Coaches in Kerman. International Journal of Advanced Biological and Biomedical Research, 6(1), 66-75. 